\title{
МЕТОДИКА АНАЛИЗА ЗАТРАТ В РАМКАХ РАЗЛИЧНЫХ ПОДХОДОВ К УПРАВЛЕНИЮ ЗАТРАТАМИ НА МАШИНОСТРОИТЕЛЬНЫХ ПРЕДПРИЯТИЯХ
}

\author{
(c) 2019 Стрельцова Дарья Алексеевна \\ аспирант \\ Самарский государственный экономический университет, Россия, Самара \\ E-mail: strelcova.dasha@inbox.ru
}

В статье рассмотрены стратегический и оперативный подходы к управлению затратами, обосновано выделение тактического подхода; выявлены основные методы анализа затрат, на основе которых предложены методические рекомендации по проведению анализа затрат на машиностроительных предприятиях.

Ключевые слова: методы анализа затрат, оперативный, тактический, стратегический подходы к управлению затратами, факторы, цепочка ценностей, CVP-анализ.

В последнее время наибольшее внимание представляют вопросы о способах и возможностях сокращения затрат на производство продукции. Достаточно много исследователей рассматривают проблемы минимизации затрат на предприятиях, однако при постоянных изменениях экономической среды остаются вопросы, требующих решения. К тому же в условиях глобализации экономик, совершенствовании информационных технологий многие проблемы требует доработок или новых решений.

Крупнейшей отраслью промышленности России является машиностроительный комплекс, объединяющий в себе совокупность отраслей, которые характеризуются сложными связями. Продукция машиностроительных предприятий характеризуется сложностью производства, многодетальностью и высокой наукоемкостью, а также наличием высоких требований к сырью и его использованию. При производстве такой продукции, предприятия нуждаются в больших ресурсах и затратах, поэтому поиск методов сокращения затрат становится всё более востребованным для машиностроительных предприятий. Важнейшей составной частью системы управления затратами является анализ затрат, который необходим в целях оценки эффективности использования ресурсов и выявления резервов снижения производственных затрат.

При формировании системы управления затратами на машиностроительных предприятиях необходимо выделять блоки анализа затрат, ориентированные на различные цели и временные периоды осуществления и отдачи затрат. Некоторые исследователи в экономической литера- туре выделяют стратегический и оперативный подходы к управлению затратами. Например, О.Н. Есина, Н.Н. Терещенко, С.В. Трусова под основной целью стратегического подхода при анализе и оценке затрат понимали: «увеличение его конкурентных преимуществ в действующих условиях внешней и внутренней среды», а под целью оперативного подхода при оценке затрат понималось: «увеличение прибыли фирмы в краткосрочном периоде при снижении затрат и оптимизации их состава и структуры» [1]. Согласно О.В. Савиной методы стратегического управления производственными затратами на предприятии используются для достижения долгосрочных целей и решения перспективных задач хозяйствующего субъекта [4]. Однако, при сложившейся производственно-хозяйственной практике машиностроительных предприятий выделение двух подходов не вполне соответствует реальности. Оперативный подход на машиностроительных предприятиях подразумевает под собой анализ фактических производственных данных и разработку плановых показателей на краткосрочные периоды (смена, сутки, пятидневка, декада, квартал) применительно к определенному объекту исследования (партия заготовок, деталей, сборочных единиц и др.). На величину затрат при этом влияет применяемая система оперативно-производственного планирования. Предлагаемые некоторыми экономистами мероприятия, такие как: определение фактической себестоимости производимой продукции, резервов её снижения и др., в рамках оперативного подхода следует относить в тактический этап анализа затрат. То есть, методика 
анализа затрат должна включать в себя оперативный, тактический и стратегический подходы.

Общие составляющие анализа затрат при любом подходе представляются одинаковыми. К ним можно отнести анализ структуры и динамику затрат, их эффективности, резервов сокращения. Однако виды затрат, алгоритмы анализа будут различаться в зависимости от применяемых подходов, а также в рамках одного подхода они будут различны в зависимости от поставленных целей, задач, а также специфики объекта проведения анализа.

Например, в рамках оперативного подхода в качестве объекта анализа выступает производственная стадия предприятия с определенным типом производства (единичным, серийным, массовым). Применительно к единичному типу производства, в зависимости от используемой системы планирования (позаказной ли комплектно-узловой), а также технической документацией на заказ, помимо производственных затрат необходимо учитывать затраты на конструирование, проектирование, разработку технологических процессов, изготовлению оснастки.

При тактическом подходе, как правило, рекомендуется анализировать общую сумму затрат (по статьям калькуляции и по элементам затрат), анализ затрат на один рубль продукции, анализ себестоимости продукции, работ, услуг. Данные рекомендации справедливы, но их можно дополнить с учетом структуры составляющих анализа в любом подходе (анализ структуры и динамики затрат, их эффективности и резервов сокращения), а также необходимостью исследования затрат, не включенных в себестоимость продукции, а возмещаемой из чистой прибыли.

При стратегическом подходе анализа затрат следует выделить такие методы его проведения, как: анализ затратообразующих факторов, цепочка ценностей; эффекты масштаба и опыта; анализ добавленной стоимости, CVP-анализ, метод установления альтернативных затрат, использование диаграмм Исикавы.

Важнейшим инструментом стратегического анализа затрат является цепочка ценностей, основная идея которой была развита М. Портером в 1985 г. Она представляет собой набор стратегически связанных видов деятельности, характеризующий собой последовательность действий предприятия, направленных на преобразование ресурсов в конечный продукт. Анализ цепочки ценностей позволяет исследовать затраты и их движение по видам деятельности, внутри этих видов деятельности, а также помогает выделять возможные источники повышения конкурентоспособности предприятия.

Эффект масштаба подразумевает достижение более низких издержек на единицу продукции по сравнению с конкурентами за счет увеличения объема производимой продукции и минимизации условно-постоянных затрат. Согласно эффекту опыта затраты на производство единицы продукции снижаются на определенный процент при каждом удвоении продукции. Эффект опыта приводит к установлению лидерства по затратам за счет накопления опыта при повторном изготовлении одного вида продукции.

Одним из важнейших методов анализа затрат на предприятии является исследование затратообразующих факторов. Выделяют функциональные затратообразующие факторы и структурные затратообразующие факторы. К функциональным затратообразующим факторам относят факторы, определяющие внутренние ресурсы предприятия, качество используемой рабочей силы, эффективность использования ресурсов, связи с заказчиками и поставщиками и др. К структурным затратообразующим факторам относят степень интеграции, объем инвестиций, опыт производственной деятельности и пр. Применение такого метода помогает оценить влияние затратообразующих факторов на величину затрат предприятия и выявить возможности для приобретения предприятием конкурентных преимуществ.

С помощью метода добавленной стоимости рассматриваются отдельные определенные объекты, которые формируют затраты предприятия. Такими объектами могут быть: определенные производственные структуры, а также стадии, переделы производственного процесса предприятия. Анализ затрат и управление ими при данном методе способствует максимизации добавленной стоимости. Однако необходимо учитывать, что в анализ не включаются материальные ресурсы, а итоговые расчеты добавленной стоимости основаны на данных бухгалтерского баланса.

Метод альтернативных затрат обеспечивает используется при поиске и применении стратегических решений в части управления затратами на основе оценки альтернативных вариантов 
(стратегий) хозяйственно-производственных решений. Однако следует учесть, что при данном подходе анализируются только такие затраты, которые изменяются при выборе альтернативного варианта (альтернативной стратегии).

Довольно распространенный метод стратегического анализа - CVP-анализ (анализ «затраты-объем-прибыль»). Он позволяет выявить оптимальные пропорции между постоянными и переменными затратами, объемом реализации, определить точку безубыточности, маржинальный доход, производственный леверидж и др. Метод основан на делении затрат на постоянные и переменные. Большая роль при выборе стратегии поведения производственного предприятия отводится показателю маржинального дохода, который представляет собой построение отчета о прибылях и убытках по принципу разделения затрат в зависимости от их поведения. При использовании CVP-анализа следует учитывать, что существуют полупеременные и полупостоянные затраты, которые снижают точность расчетов.

ABC-метод, как метод анализа и управления затратами предприятия, позволяет осуществлять стратегический анализ и управление затратами по видам деятельности предприятия. АВС-метод исходит из того, что деятельность - это причина затрат, а продукция (объект затрат) - результат деятельности. АВС-метод дает возможность разделить учет (и структурные подразделения компании) на более важные и менее значимые и выявить наиболее проблемные зоны, которые могут стать (или являются) источниками убытков.

Одним из методов стратегического анализа затрат является диаграмма Исикавы. Диаграмма представляет собой график, на основе которого выявляются, исследуются основные причинноследственные факторы, связи между ними и последствия в анализируемой проблеме, предупреждаются нежелательные факторы и причины.

Рассмотрев различные подходы и методы анализа затрат, можно сформулировать рекомендации по его проведению на машиностроительных предприятиях.

Начальным элементом анализа затрат является этап постановки цели, задач, выделения его объекта, что связано с наличием у машиностроительного предприятия комплекса разнородных производств и видов деятельности, а также и технологические стадии: заготовительную, обрабатывающую, сборочную. На заготовительной стадии формируются затраты на предварительную подготовку заготовок, на производство поковок, в литейных цехах - на изготовление разного рода отливок, а также затраты, связанные с хранением заготовок на складах и потери, связанные с пролеживанием средств в незавершенном производстве. На обрабатывающей стадии формируются затраты на производство деталей либо напрямую, либо через склад готовых деталей. Здесь опять возникают затраты, связанные с хранением деталей в незавершенном производстве. На сборочной стадии формируются затраты на сборку, и опять же затраты на хранение деталей на складе.

Все вышеназванные затраты связаны с производством продукции. Следует также учитывать, что машиностроительное предприятие может осуществлять и различные виды деятельности: маркетинговую, финансовую, инвестиционную, научно-исследовательскую, опытноконструкторскую и др., каждая из которых формирует свои специфические затраты.

Большое значение, для предприятия играют внешние факторы. Поэтому следующим этапом анализа может быть изучение окружающей среды предприятия, в которой необходимо выделять макросреду и микросреду предприятия. Анализ окружающей среды предприятия целесообразно проводить по традиционной схеме с выделение в макроокружении отдельных составляющих (экономика, политика, общество, законодательство, технология). В непосредственном окружении предприятия необходимо выделять такие компоненты, как: покупатели, поставщики, конкуренты, посредники (торговые, финансовые, маркетинговые), государственные структуры. Во внутренней среде предприятия следует выделять элементы по функциональным сферам деятельности (производство, маркетинг, финансы, персонал, организационная структура).

Основываясь на предложенном ранее выделении оперативного, тактического и стратегического подходов, можно представить вышерассмотренные методические рекомендации по анализу затрат машиностроительного предприятия в виде схемы (см. рис. 1).

Особую важность в предложенных методических рекомендациях обретает этап выявления основных факторов и взаимосвязей, влияющих на затраты с оценкой возможных резервов их 


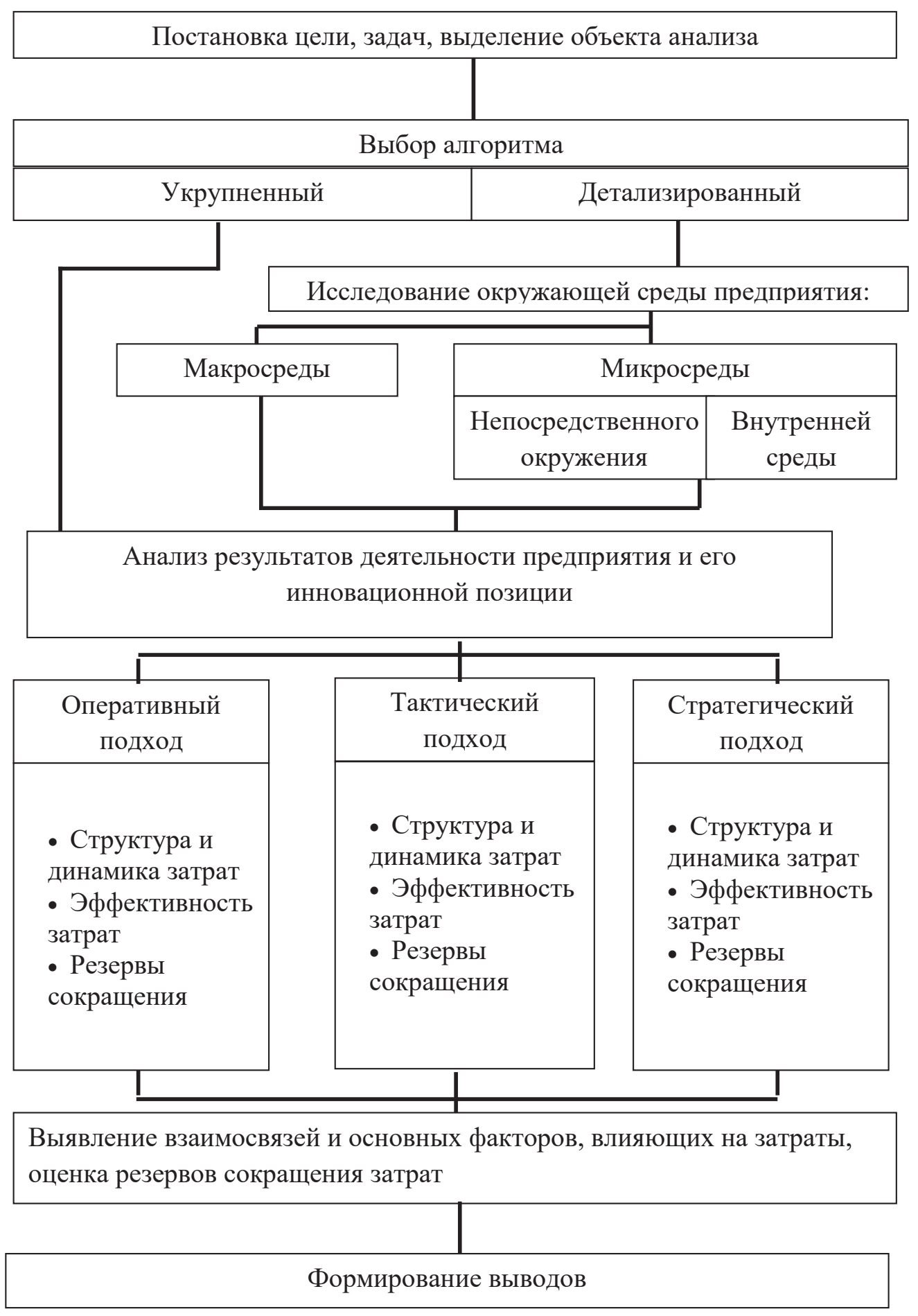

Рис.1. Методические рекомендации по анализу затрат машиностроительного предприятия 
сокращения. Необходимо учитывать, что большинство отечественных предприятий машиностроительного комплекса характеризуется значительной технико-технологической отсталостью своей материально-технической базы и низкой инновационной активностью. В связи с этим значимое сокращение затрат и достижение конкурентных преимуществ можно добиться только при комплексном преобразовании применяемого оборудования, разработок и внедрения новых продуктов, технологических инноваций. Все вышеперечисленное требует довольно большого объема капитальных и текущих затрат. Поэтому можно увидеть тесную взаимосвязь между затратами, реализуемыми в рамках оперативного и тактического подходов, и затратами, осуществляемыми в рамках стратегического подхода.

В настоящее время в экономической литературе большое внимание уделяется расчетным алгоритмам, основанным на подходе управленческого учета, разработанным зарубежными учеными. Без сомнения такие расчетные алгоритмы должны применяться на предприятиях при анализе затрат, особенно в рамках стратегического подхода.

Однако следует повысить значимость применения предприятиях традиционных, отечественных подходов и методов анализа затрат, в частности, особенно при оперативном и тактическом подходов, анализа и соблюдения нормативной базы, анализа себестоимости продукции по элементам, статьям затрат, смет, калькуля- ций и др. Уже при анализе этих составляющих выявляются предварительные резервы снижения текущих затрат.

При исследовании динамики затрат по отдельным статьям, элементам весьма полезно сравнивать их темпы роста с темпами роста объема производства, оптовых цен на используемые при производстве ресурсы, соответствующие коэффициенты опережения.

В рамках стратегического подхода при анализе затрат необходимо исследовать затраты на научные исследования и разработки, связанные с внедрением новых продуктов и технологических процессов; на проектно-конструкторские работы, связанные с технологическим оснащением, организацией производства и подготовительным этапом выпуска новой продукции; на технологическую подготовку производства; на приобретение машин и оборудования; на маркетинговые исследования; на приобретение прав на патенты, лицензий на использование изобретений; на приобретение программных средств, связанных с осуществлением инноваций.

Анализ и оценка рассмотренных показателей в соответствии с поставленными целями, задачами и объектами анализа в статике, в динамике, выявление отклонений способствует выявлению основных факторов, оказывающих влияние на затраты. Также полученные данные помогают сформулировать выводы и определить возможные резервы снижения затрат, определиться с мероприятиями по их сокращению.

\section{Библиографический список}

1. Есина О.Н., Терещенко Н.Н., Трусова С.В. Методика анализа затрат предприятия на основе синтеза стратегического и оперативного подходов; Микроэкономика. Издательство: Научно-исследовательский институт экономических стратегий (Москва) - 2015. 1, с. 68.

2. Комплексное планирование промышленных предприятий. Базовые принципы, методика, ИТ-обеспечение / Г. Павеллек.-М.: Альпина Паблишер, 2015

3. Наугольнова И.А. Сводный учет затрат на производство и калькулирование себестоимости продукции на промышленных предприятиях с мелкосерийным и единичным типом производства // Финансы и управление.-2018.- № 1.- C. 31-39. DOI: 10.25136/2409-7802.2018.1.21325 URL: https://nbpublish.com/library_ read_article.php?id=21325

4. Савина О.В. Использование методов стратегического анализа производственных затрат предприятия. Известия Тульского Государственного Университета. Экономические и юридические науки.; с. 62-69

5. Управление затратами предприятия (организации): учебное пособие / М.С. Кузьмина, Б.Ж. Акимова.- М.: КНОРУС, 2015.- 320с. - (Бакалавриат)

6. Управленческий и производственный учет: учебный комплекс для студентов вузов / Колин Друри; пер с англ. [В.Н. Егорова]. - 6-е изд.- М.: ЮНИТИ-ДАНА, 2012.- 1423 с. - (Серия «Зарубежный учебник») 
7. Якупов И.Ф. Основные принципы и методы управления затратами на производство продукции [Текст] // Проблемы современной экономики: материалы II Междунар. науч. конф. (г. Челябинск, октябрь 2012 г.). Челябинск: Два комсомольца, 2012.- C. 131-134.- URL https://moluch.ru/conf/econ/archive/56/2635/ (дата обращения: 11.04.2019). 